\title{
Virus de la necrosis hipodérmica y hematopoyética infecciosa (IHHNV) y virus del síndrome de Taura (TSV) en camarón silvestre (Farfantepenaeus aztecus Ives, 1891 y Litopenaeus setiferus Linnaeus, 1767) de La Laguna Madre, Golfo de México
}

\author{
Infectious hypodermal and hematopoietic necrosis virus (IHHNV) and Taura syndrome \\ virus (TSV) in wild shrimp (Farfantepenaeus aztecus Ives, 1891 and Litopenaeus \\ setiferus Linnaeus, 1767) of La Laguna Madre, Gulf of Mexico
Francisco M. Guzmán-Sáenz ${ }^{1}$, Zinnia J. Molina-Garza², Roberto Pérez-Castañeda ${ }^{1}$, José C. Ibarra-Gámez ${ }^{2}$ y Lucio Galavíz-Silva ${ }^{2 *}$ \\ ${ }^{1}$ Facultad de Medicina Veterinaria y Zootecnia de la Universidad Autónoma de Tamaulipas. \\ Carretera Victoria - Mante Km. 5, Cd. Victoria, Tamaulipas, México \\ ${ }^{2}$ Laboratorio de Patología Molecular, Facultad de Ciencias Biológicas, Universidad Autónoma \\ de Nuevo León.Nuevo León, Ave. Universidad S/N, Cd. Universitaria, \\ San Nicolás de los Garza, Nuevo Leon. CP 66451, México \\ *lgs12167@yahoo.com
}

\begin{abstract}
The occurrence of infectious hypodermal and hematopoietic necrosis virus (IHHNV) and Taura syndrome virus (TSV) in wild shrimp Litopenaeus setiferus (white shrimp) and Farfantepenaeus aztecus (brown shrimp) captured from the estuary of La Pesca in La Laguna Madre Tamaulipas, Mexico, are reported. This study was performed for histopathology and amplification of nucleic acids. The prevalence of TSV was $6.6 \%(12 / 180)$ and $4.4 \%$ for IHHNV (8/180). Most cases were observed from November to March $(15 / 180)$. The presence of these viruses in wild shrimp from the La Laguna Madre, alerts about the risk that are having the wild populations and the shrimp farms that are contiguous with the Gulf of Mexico, so it is suggested to establish a program of sanitary monitoring and to verify the impact of both viruses in the near shrimp farms of the La Laguna Madre.
\end{abstract}

Key words: Viral diseases, white shrimp, brown shrimp, histopathology, PCR

\section{Introducción}

En las últimas tres décadas se ha incrementado en forma importante el aprovechamiento de organismos acuáticos para la alimentación humana (Rodríguez \& Le Moullac 2000), sin embargo, el desarrollo de la explotación intensiva incrementa simultáneamente el riesgo de transmisión de agentes patógenos con efectos devastadores (Saulnier et al. 2000, Teunissen et al. 1998, Van de Braak et al. 2002), por lo cual es necesario aplicar
Resumen.- Se reporta la presencia del virus de la necrosis hipodérmica y hematopoyética infecciosa (IHHNV) y del virus del síndrome de Taura (TSV) en camarones silvestres Litopenaeus setiferus (camarón blanco) y Farfantepenaeus aztecus (camarón café) capturados en el estero de La Pesca, en La Laguna Madre, Tamaulipas, México. El estudio se realizó por histopatología y amplificación de ácidos nucleicos. La prevalencia de TSV fue 6,6\% (12/180) y 4,4\% para IHHNV (8/180). La mayoría de los casos se presentaron de noviembre a marzo (15/180). La presencia de estos virus en camarones silvestres de La Laguna Madre, alerta sobre el riesgo en que se encuentran las poblaciones silvestres y las granjas camaroneras colindantes con el Golfo de México, por lo que se sugiere establecer un programa de monitoreo sanitario y verificar el impacto de ambos virus en camarones de granjas vecinas a $\mathrm{La}$ Laguna Madre.

Palabras clave: Enfermedades virales, camarón blanco, camarón café, histopatología, PCR

programas de monitoreo sanitario preventivos en los ecosistemas silvestres y en las granjas (Bachere 2000). México, por su ubicación geográfica, tiene las mejores condiciones naturales para el desarrollo de la camaronicultura ya que cuenta con aproximadamente $11,500 \mathrm{Km}$ de litorales (Dorf et al. 2005), pero el obstáculo más grande en los cultivos de camarón (aún en el ámbito mundial) han sido las enfermedades, siendo las de etiología viral las que han provocado las mayores pérdidas (Chang et al. 2004, Páez-Osuna 2005, Bondad- 
Reantaso et al. 2005). Sobresalen en el país las pérdidas causadas por el virus de la necrosis hipodérmica y hematopoyética infecciosa (IHHNV) en cultivos de Litopenaeus stylirostris (Stimpson, 1874) (Lightner et al. 1992) y los virus del síndrome de Taura (TSV) y de la mancha blanca (WSSV) en L. vannamei (Boone, 1931) (Lightner \& Reedman 1998, Galavíz-Silva et al. 2004, Molina-Garza et al. 2008), igual que en países asiáticos (Briggs et al. 2005, Brock 2008, Stentiford et al. 2009) y americanos (Aguado et al. 2008).

Los signos clínicos del síndrome de Taura (TS) inician a los 14-40 días después de la siembra en L. vannamei de 0,1-5 g. En la fase preaguda, los camarones moribundos presentan expansión de los cromatóforos rojos en apéndices (urópodos, telson, pleópodos) y en la superficie general del cuerpo con cutícula suave (debido a que regularmente coincide con el estadio D del ciclo de muda). Si la infección es severa los camarones mueren en esta fase. El análisis histopatológico revela áreas de necrosis multifocal en epitelio cuticular en la superficie general del cuerpo, apéndices, branquias, intestino, esófago y estómago. Las lesiones cuticulares multifocales son prominentes, caracterizándose por cuerpos de inclusión esféricos, citoplasmáticos de tamaño variable $(1-20 \mu \mathrm{m})$ eosinofílicos a basofillicos, núcleos cariorécticos o picnóticos. Los sobrevivientes desarrollan lesiones cuticulares melanizadas y se alimentan normalmente, recuperándose de la infección, alcanzando la fase crónica. El análisis histológico asemeja la enfermedad bacteriana del caparazón (Hasson et al. 1995, Lightner et al. 1995).

El IHHNV causa mortalidades de hasta el $90 \%$ en $L$. stylirostris. Los juveniles en la fase aguda, cesan de alimentarse, pierden movilidad y presentan opacidad en la musculatura abdominal, la debilidad es extrema y causa una alta mortalidad o bien suscita el canibalismo. En $L$. vannamei es una enfermedad de curso crónico desarrollando el síndrome de la deformidad y enanismo con baja mortalidad, afectando considerablemente el crecimiento y aumento de peso (Morales-Covarrubias et al. 1996, Primavera \& Quinitio 2000). El IHHNV infecta tejidos de origen ectodérmico (epidermis, epitelio intestinal, cordón y ganglio nervioso) y mesodérmico (tejido hematopoyético, glándulas antenales, gónadas, órgano linfoide, tejido conectivo y músculo estriado). Los núcleos infectados se observan hipertrofiados, con cuerpos de inclusión intranucleares tipo Cowdry A, eosinofílicos y cromatina marginada (Lightner et al. 1992). Se ha detectado el IHHNV en camarones silvestres en Ecuador, Occidente de Panamá y costa oeste de México (Nunan et al. 2001, Tang \& Lightner 2001).
La zona norte de La Laguna Madre es área de crianza del camarón café, Farfantepenaeus aztecus (Ives, 1891); camarón blanco, Litopenaeus setiferus (Linnaeus, 1767) y camarón rosado, F. duorarum (Burkenroad, 1939) que son capturados en la zona lagunar y costera de Tamaulipas donde alcanzan etapas juveniles y preadultas (WakidaKusunoki et al. 2008). TSV es altamente infectivo para L. setiferus, descrito como hospedero natural y experimental, junto con $F$. duorarum y $F$. aztecus aunque los dos últimos permanecen como portadores (OIE 2006). Sobre IHHNV se tienen reportes de infecciones experimentales en $L$. setiferus, F. duorarum y F. aztecus, pero se asevera que es enzootico en peneidos silvestres del Indopacífico, Ecuador, Panamá y oeste de México (Lightner 1996), sin embargo, no existen reportes sobre la prevalencia de TSV e IHHNV en camarones silvestres del Golfo de México.

Para la detección oportuna de estos virus la histopatología convencional es aún el método vigente (Morales-Covarrubias et al. 1999, Pantoja et al. 1999), pero es necesaria la confirmación con técnicas de diagnóstico moleculares debido a que los cambios histopatológicos entre IHHNV y el WSSV pueden confundirse. Lo mismo ocurre entre TSV y el virus de la cabeza amarilla (YHV); (Lightner 1996, OIE 2006). Las granjas de camarón del estado de Tamaulipas, México, en la actualidad, cultivan L. vannamei; esta especie es altamente susceptible al TSV, aumentando el riesgo de una epizootia al existir camarones silvestres positivos a esta enfermedad en aguas cercanas (Lotz et al. 2003). El presente estudio determina la prevalencia de agentes etiológicos virales en camarones silvestres de La Laguna Madre, Tamaulipas durante un muestreo anual y analiza el grado de asociación estadística entre la presencia de los virus y la talla, sexo y especie de los camarones estudiados, lo cual permitirá implementar las medidas de bioseguridad pertinentes en las granjas cercanas de las costas del estado.

\section{Material y métodos}

\section{Área de estudio}

El estero de La Pesca (2347'31.49"N,97²7' 14.78"W), se encuentra al sur de La Laguna Madre, en el municipio de Soto La Marina, estado de Tamaulipas, México, a 180 $\mathrm{km}$ al oriente de la capital del Estado $\left(27^{\circ} 40^{\prime}-22^{\circ} 12^{\prime} \mathrm{N}\right.$, $97^{\circ} 08^{\prime}-100^{\circ} 08^{\prime} \mathrm{W}$ ) a $3 \mathrm{~m}$ sobre el nivel del mar (Fig. 1), presenta una precipitación pluvial media anual de 730 mm y temperatura media anual de $23^{\circ} \mathrm{C}$, es hábitat natural de L. setiferus, F. aztecus y F. duorarum (Wakida et al. 2008). Los valores mínimos de salinidad son de 35-42 ups en abril con temperaturas de $23-28^{\circ} \mathrm{C}$, mientras que 


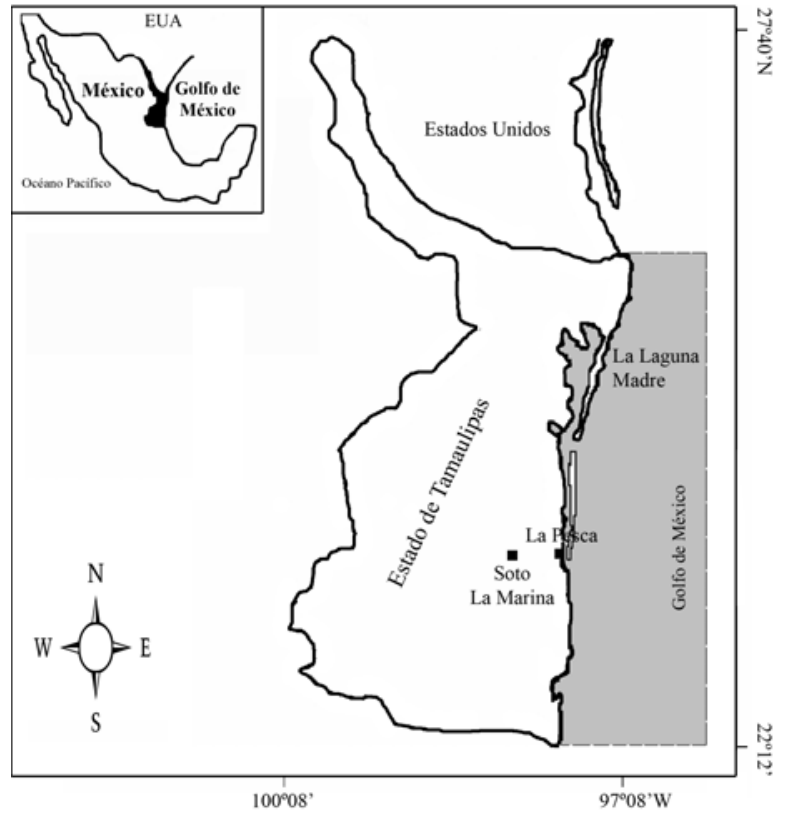

Figura 1

Ubicación geográfica del área de estudio, en la costa este de Soto La Marina, Tamaulipas

Geographic location of the study area, East coast of Soto La Marina, Tamaulipas

los mayores ocurren en septiembre, oscilando entre 3850 ups con temperaturas de $28-34^{\circ} \mathrm{C}$ (Ocaña-Luna 1999).

\section{Recolecta y preservación}

Se programaron recolectas mensuales de octubre 2005 a septiembre 2006, capturándose con atarraya de $2,5 \mathrm{~cm}$ de luz, un total de 720 camarones silvestres de las especies L. setiferus y F. aztecus, identificados a nivel de especie de acuerdo a Pérez-Farfante (1988). Se registró sexo, talla y peso; la longitud total osciló entre $44 \mathrm{~mm}$ y $178 \mathrm{~mm}$. El tamaño de muestra fue estimado de acuerdo a recomendaciones aplicadas a nivel internacional para vigilancia de patógenos exóticos por no existir registros de éstos en el área de estudio. Esta recomendación se basa en una prevalencia del $2-5 \%$ con un límite de confianza del 95\% (Ossiander \& Wedermeyer 1973, Bondad-Reantaso et al. 2001). En esta investigación, para una población entre 500-1000 ejemplares, el tamaño de muestra osciló entre 54-127 y 55-136 organismos (prevalencias entre $2 \%$ y $5 \%$, respectivamente), analizándose 15 ejemplares de 65-66 capturados por recolecta, para un total de 180 seleccionados en forma aleatoria de $720(25 \%)$, con lo cual se sobrepasa el tamaño de muestra requerido (López-Téllez et al. 2009).
Cada camarón fue analizado macroscópicamente en busca de lesiones externas, expansión de cromatóforos, variación en color del hepatopáncreas y branquias, posteriormente se les realizó examen microscópico en fresco de hepatopáncreas, branquias, intestino y músculo (Lightner 1996). Los ejemplares se fijaron por inyección e inmersión con solución Davidson (Bell \& Lightner 1988) y se transportaron al laboratorio de la Facultad de Medicina Veterinaria y Zootecnia, Universidad Autónoma de Tamaulipas, para procesarlas para el análisis histopatológico.

Una muestra de branquias, tejido subcuticular y pleópodos (50-100 mg) se depositaron en $1 \mathrm{ml}$ de etanol 96\% para la extracción de ácidos desoxirribonucleicos (ADN) y confirmar la presencia de IHHNV por reacción en cadena de la polimerasa (PCR). Una segunda muestra de tejidos se preservó en $1 \mathrm{~mL}$ de Tri Reagent ${ }^{\circledR}$ (Molecular Research Center Inc., Ohio, USA) para la extracción de ácidos ribonucleicos (ARN) y diagnóstico de TSV por reverso transcripción y PCR (RT-PCR). Las muestras en etanol y Tri Reagent ${ }^{\circledR}$ se conservaron a $4^{\circ} \mathrm{C}$ y se enviaron a la Facultad de Ciencias Biológicas, Universidad Autónoma de Nuevo León, para análisis molecular.

\section{Análisis histopatológico}

Los camarones fueron procesados por la técnica histológica de rutina y se tiñeron con hematoxilina-eosina, según el procedimiento descrito por Bell \& Lightner (1988). Posteriormente se examinaron al microscopio óptico, todos los órganos internos, primer y quinto segmento abdominal. Las microfotografías de lesiones histopatológicas características de TSV o IHHNV fueron obtenidas con una cámara digital Moticam ${ }^{\circledR} 2000$ (Motic China Group, Ltd., Causeway Bay, Hong Kong) adaptada en un microscopio Leica ${ }^{\circledR}$ DME (Bannockburn, IL 60015 USA).

\section{Análisis confirmatorio por PCR}

Las muestras para el diagnóstico molecular de IHHNV se maceraron con un pistilo desechable en $0,6 \mathrm{~mL}$ de solución DTAB (dodecyltrimethylammonium bromide), incubándose a $75^{\circ} \mathrm{C} / 5 \mathrm{~min}$. Después de enfriarse a temperatura ambiente se les agregó $0,7 \mathrm{~mL}$ de cloroformo, centrifugando a $12000 \mathrm{~g} / 5 \mathrm{~min}$. La fase acuosa se transfirió a un nuevo tubo para agregar $100 \mathrm{~mL}$ de CTAB (cetyltrimethylammonium bromide), según las instrucciones del fabricante (IQ2000 IHHNV Detection and Prevention System, Farming IntelliGene Tech. Corp, Taiwan), conservando el ADN en agua bidestilada a $20^{\circ} \mathrm{C}$ hasta su uso posterior. Para el PCR, primero se agregaron $12,5 \mu \mathrm{L}$ del reactivo premezclado que contiene amortiguador de reacción, dNTPs (deoxinucleotidos 
trifosfatados) y primers IHHNV específicos (que amplifican fragmentos de 644 y 438) con $0,5 \mu \mathrm{L}$ de IQzyme ADN polimerasa y $2 \mu \mathrm{L}$ del ADN extraído de las muestras (o controles positivos). El programa de amplificación fue el recomendado por el fabricante. Los productos de PCR se analizaron por electroforesis en geles de agarosa al $2 \%$ en TBE (Tris-borato-EDTA) y examinados al final de la corrida en un transiluminador de luz UV Fotodyne ${ }^{\circledR}$, (Hartland, WI, USA).

Para el análisis de TSV, las muestras fueron maceradas en el Tri Reagent ${ }^{\circledR}$ con pistilos desechables, de acuerdo al protocolo del fabricante (MRC, Inc.) para conservarse finalmente en agua bidestilada tratada con dietilpirocarbonato. Las reacciones de RT-PCR se realizaron con $A M V$ transcriptasa reversa y $T f l$ ADN polimerasa en volúmenes de reacción de $50 \mu \mathrm{L}$ incluyendo $5 \mu \mathrm{L}$ del ARN extraído de las muestras, según las instrucciones del protocolo del fabricante del kit Access RT-PCR System (Promega, Madison WI, USA). Los iniciadores específicos para TSV fueron sintetizados por Invitrogen (Carlsbad, California, EUA) con la secuencia descrita previamente por Nunan et al. (1998). El programa de amplificación consistió en un paso inicial de $48^{\circ} \mathrm{C}$ por 45 min para la reverso transcripción y $94^{\circ} \mathrm{C}$ por 2 min para inactivar la enzima $A M V$ RT. Después se continuó con 40 ciclos de amplificación $\left(94^{\circ} \mathrm{C} / 30 \mathrm{~s}, 60^{\circ} \mathrm{C}\right.$ $/ 1 \mathrm{~min}$ y $68^{\circ} \mathrm{C} / 2 \mathrm{~min}$ ). Los productos de RT-PCR fueron analizados por electroforesis en geles de agarosa al $1 \%$, conteniendo $0,5 \mu \mathrm{g} \mathrm{mL} \mathrm{mL}^{-1}$ de bromuro de etidio en amortiguador TBE al 0,5 X (Sambrook \& Russell 2001).

\section{Análisis estadístico}

Se determinó la dependencia entre la presencia de la (s) enfermedad (es) viral (es) y las características registradas del sexo, talla y especie mediante el análisis de tablas de contingencia $\left(X^{2}, P \leq 0,05\right)$, utilizando el programa Statistica v.6 (StatSotf Inc., Tulsa, OK, USA), donde la hipótesis nula (Ho) se estableció para la positividad del diagnóstico del virus independiente de las variables y la hipótesis alterna (Ha) para la positividad del diagnóstico del virus no independiente de las variables.

\section{Resultados}

La mayor prevalencia de casos ocurrió entre noviembre a marzo, con el 8,33\% de ejemplares positivos a IHHNV y TSV (15/180). Durante julio a septiembre los hallazgos fueron esporádicos, con prevalencias de 0,55 a $1,11 \%$ (1-2/180; Fig. 2). En ambas patologías, los cuerpos de inclusión fueron escasos y no se detectaron cuadros clínicos serios en el análisis macro y microscópico.

Los cuerpos de inclusión citoplásmicos observados, fueron esféricos y de tamaño variable (Fig. 3a, b), con áreas de necrosis, cariorexis y picnosis nuclear en epitelio cuticular de la superficie corporal (Fig. 3c), apéndices e intestino compatibles con TSV en 12 camarones, representando el $6,6 \%$ de un total de 180 camarones (Tabla 1). Los camarones positivos a TSV se distribuyeron por género en tres machos de $F$. aztecus y 9 hembras (8 de L. setiferus y uno de F. aztecus), clasificados en el rango de camarones pequeños (Tabla 2). El análisis de PCR confirmó la presencia de amplicones de 231 pb en 5 de los 12 casos (Fig. 4).

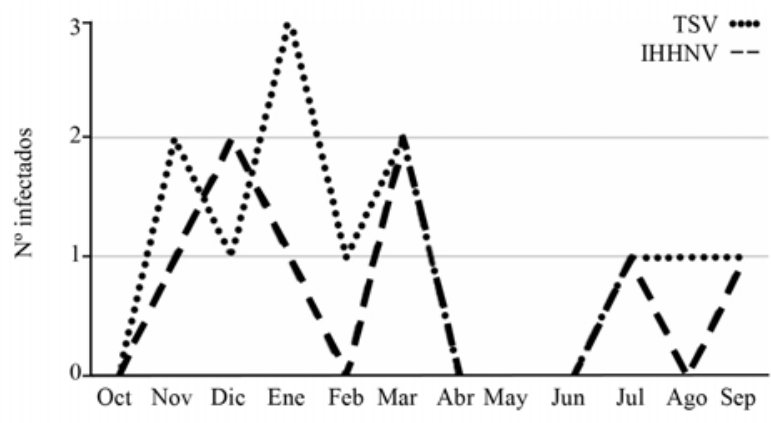

Figura 2

\section{Frecuencia de IHHNV y TSV en camarón silvestre} durante el año de muestreo

Frequency of IHHNV and TSV-positive wild shrimp through the annual survey

Tabla 1

Camarones en los que se detectaron cuerpos de inclusión de TSV

Shrimps in which inclusion bodies of TSV were detected

\begin{tabular}{rrrrrl}
\hline $\mathrm{N}^{\circ}$ & LT Tmm & LCmm & Pesog & Sexo & Especie \\
\hline 1 & 56 & 17 & 0,87 & Hembra & L. setiferus \\
2 & 58 & 20 & 0,75 & Hembra & L. setiferus \\
3 & 64 & 23 & 1,87 & Hembra & L. setiferus \\
4 & 58 & 18 & 1,32 & Hembra & L. setiferus \\
5 & 66 & 24 & 1,80 & Hembra & L. setiferus \\
6 & 64 & 19 & 1,76 & Hembra & L. setiferus \\
7 & 65 & 19 & 1,97 & Hembra & F. aztecus \\
8 & 63 & 18 & 1,98 & Macho & F. aztecus \\
9 & 56 & 16 & 1,23 & Macho & F. aztecus \\
10 & 44 & 10 & 0,64 & Hembra & L. setiferus \\
11 & 54 & 12 & 1,38 & Macho & F. aztecus \\
12 & 59 & 22 & 2,06 & Hembra & L. setiferus
\end{tabular}

LT: Longitud total LC: Longitud del cefalotórax 

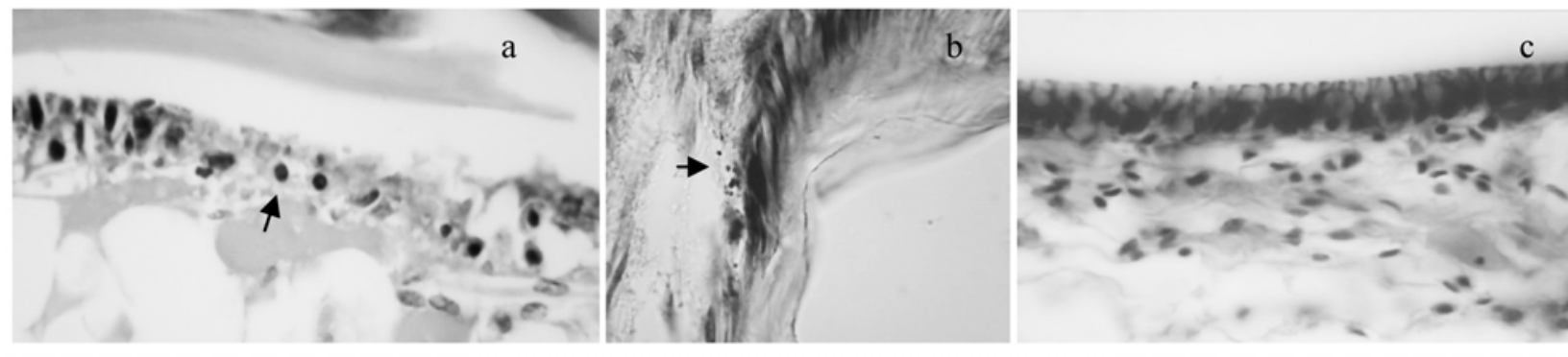

Figura 3

Epitelio cuticular de camarón mostrando cuerpos de inclusión citoplásmicos de TSV (a, b, flecha) y picnosis nuclear con cariorexis en epitelio (c). H \& E a, c: 600X; b: 200X

Cuticular epithelium with cytoplasmic inclusion bodies of TSV (a, b, arrow) and piknotic or karyorrhectic nuclei in epithelial cells (c). H \& E a, c: 600X; b: 200 X

Tabla 2

Frecuencia de camarones con o sin el virus del TSV y significancia estadística respecto al sexo, especie y talla

Frequency of shrimps with or without TSV and statistical significance with respect sex, species and size

\begin{tabular}{|c|c|c|c|c|c|c|c|c|}
\hline \multirow[b]{2}{*}{ TSV } & \multicolumn{2}{|c|}{ Sexo } & \multicolumn{2}{|c|}{ Especie } & \multicolumn{3}{|c|}{ Talla } & \multirow[t]{2}{*}{ Total } \\
\hline & Machos & Hembras & L. setiferus & F. azetcus & Pequeños & Medianos & Grandes & \\
\hline Pos & $\begin{array}{c}3 \\
(4,98)\end{array}$ & $\begin{array}{c}9 \\
(9,02)\end{array}$ & $\begin{array}{c}8 \\
(9,41)\end{array}$ & $\begin{array}{c}4 \\
(4,59)\end{array}$ & $\begin{array}{c}12 \\
(11,43)\end{array}$ & $\begin{array}{c}0 \\
(1,4)\end{array}$ & $\begin{array}{c}0 \\
(1,16)\end{array}$ & 12 \\
\hline Neg & $\begin{array}{c}61 \\
(59,02)\end{array}$ & $\begin{array}{c}107 \\
(106,02)\end{array}$ & $\begin{array}{c}113 \\
(111,59)\end{array}$ & $\begin{array}{c}55 \\
(54,41)\end{array}$ & $\begin{array}{c}135 \\
(135,56)\end{array}$ & $\begin{array}{c}18 \\
(16,6)\end{array}$ & $\begin{array}{c}15 \\
(13,83)\end{array}$ & 168 \\
\hline Total & 64 & 116 & 121 & 59 & 147 & 18 & 15 & 180 \\
\hline $\begin{array}{l}X^{2} \\
P\end{array}$ & & $\begin{array}{l}027 \\
58\end{array}$ & \multicolumn{2}{|c|}{2,075} & \multicolumn{3}{|c|}{3,407} & \\
\hline
\end{tabular}

Pos: Positivos, Neg: Negativos, $X^{2}$ : Valor de la chi-cuadrada, $P$ : Grado de dependencia estadística. Los valores esperados se citan entre paréntesis

Para IHHNV se encontraron 8 camarones con cuerpos de inclusión intranucleares y eosinofílicos (Fig. 5), representando el $4,4 \%$ de la muestra (Tabla 3). Los camarones positivos a IHHNV, estaban entre $59 \mathrm{~mm}$ y $93 \mathrm{~mm}$ de longitud total, dentro de un rango de peso de 1,80 a 3,26 g, eran cinco machos y tres hembras. Mayores detalles se presentan en las Tablas 3 y 4 . Por la técnica de PCR se confirmó el diagnóstico histopatológico en los 8 casos (Fig. 6).

Con respecto al análisis estadístico, la presencia de los virus IHHNV y TSV fue independiente del sexo, especie y talla del camarón, debido a que la significancia estadística $P$ fue mayor a 0,05 (Tablas 2 y 4 ).
Tabla 3

Camarones en los que se detectaron cuerpos de inclusión de IHHNV

Shrimps in which inclusion bodies of IHHNV were detected

\begin{tabular}{cccccl}
\hline $\mathrm{N}^{\circ}$ & LT mm & LC mm & Pesog & Sexo & \multicolumn{1}{c}{ Especie } \\
\hline 1 & 59 & 13 & 2,01 & Macho & L. setiferus \\
2 & 66 & 24 & 1,80 & Macho & L. setiferus \\
3 & 82 & 27 & 2,63 & Macho & L. setiferus \\
4 & 65 & 19 & 1,97 & Macho & F. aztecus \\
5 & 64 & 14 & 1,98 & Macho & F. aztecus \\
6 & 71 & 26 & 2,03 & Hembra & F. aztecus \\
7 & 93 & 36 & 3,26 & Hembra & L. setiferus \\
8 & 72 & 28 & 2,03 & Hembra & F. aztecus \\
\hline
\end{tabular}

LT: Longitud total LC: Longitud del cefalotórax 


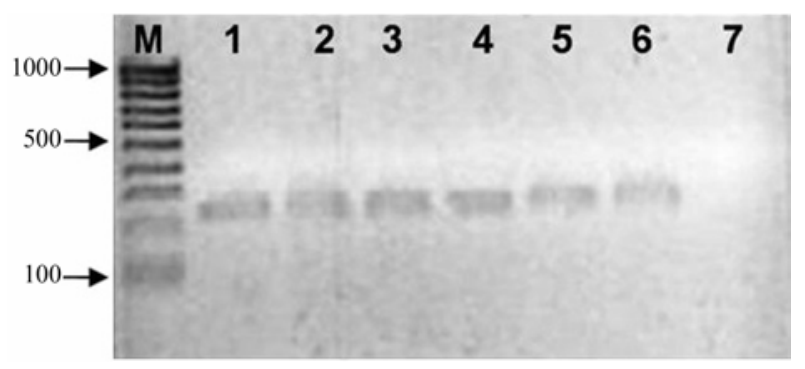

Figura 4

Banda de 231 pb indicativo de la presencia de TSV, resultado del PCR realizado con branquias, pleopodos o tejido subcuticular como templado de cADN. Carril M: Marcador molecular de 100 pb de ADN. 1: Control positivo, 2-4: Muestras de L. setiferus. 5-6: Muestras de F. aztecus. 7: Control negativo

The $231 \mathrm{pb}$ band, indicative of the presence of TSV, resulting from a PCR assay, using homogenized gills, pleopods or subcuticular tissues as cDNA template. Lane M: 100 bp DNA molecular weight ladder. 1: Positive control. 2-4: Sample from L. setiferus. 5-6: Samples from F. aztecus. 7: Negative control

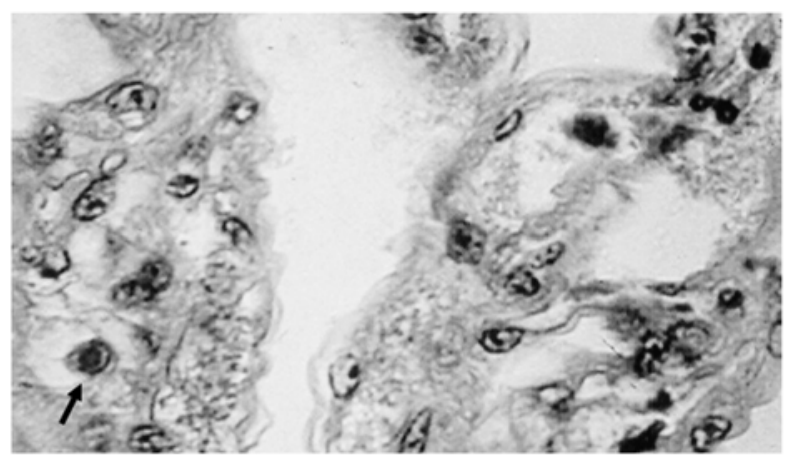

Figura 5

Branquia de camarón con núcleo hipertrofiado y cuerpo de inclusión eosinofílicoCowdry tipo

A, característico de IHHNV (flecha). H \& F, 100X

Typical IHHNV- positive shrimp gills with characteristic hypertrophied nuclei and eosinophilic inclusion bodies Cowdry type A (arrow). H \& F, 100X

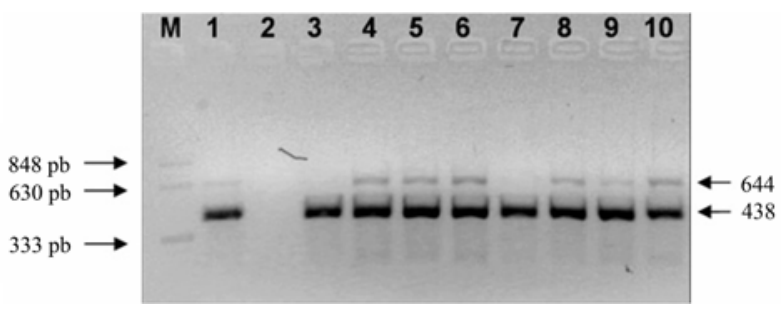

Figura 6

Gel de agarosa teñido con bromuro de etidio donde se muestra el ADN amplificado de camarones positivos a IHHNV, recolectados en La Laguna Madre, Tamaulipas. Carril M: Marcador de peso molecular (provisto con el estuche de diagnóstico IQ IHHNV). Carril 1: Control positivo. 2: Control negativo. 3-6: ADN extraído de $L$. setiferus. 7-10: Muestras deF. aztecus

Ethidium bromide-stained agarose gel of IHHNV DNA extracted from wild shrimps from Laguna Madre, Tamaulipas. Lane M: Molecular weight marker (provided with the kit IQ IHHNV). Lane 1:

Positive control. 2: Negative control. 3-6: DNA extracted from L. setiferus. 7-10: Samples from F. aztecus

\section{Discusión}

Los resultados obtenidos en la presente investigación sobre camarones positivos a IHHNV y TSV, en una zona donde no se habían detectado estos agentes patógenos, son importantes para tomar medidas preventivas, ya que incrementa el nivel de riesgo de dispersión de los virus hacia las granjas cercanas ( $740 \mathrm{Ha})$ y causar mortandades elevadas con un impacto económico serio, como lo indica Bondad-Reantaso et al. (2005) en la acuacultura de Asia. Aunque existe la posibilidad de que la dispersión ocurra de las granjas a ecosistemas silvestres, se han presentado epizootias severas por TSV en las granjas de L. vannamei ubicadas en las costas de Texas en 1995 y más recientemente en granjas en los municipios de Cameron y Willancy durante junio del 2004 (APHIS, 2004'), cercanas al área de estudio del presente trabajo. También el año pasado se reportaron casos de IHHNV en una granja de L. vannamei cercano al sitio de recolecta

${ }^{1}$ APHIS. 2004. Taura syndrome virus, United States. June 10, 2004. Impact Worksheet. Center for Emerging Issues. Centers for Epidemiology and Animal Health Animal and Plant Health Inspection Service, USDA. [en línea] <http://www.aphis.usda.gov/ animal_health/animal_dis_spec/aquaculture/downloads/ tsvirustx04.pdf_> 
Tabla 4

Frecuencia de camarones con o sin IHHNV y significancia estadística respecto al sexo, especie y talla

\begin{tabular}{|c|c|c|c|c|c|c|c|c|}
\hline \multirow[b]{2}{*}{ TSV } & \multicolumn{2}{|c|}{ Sexo } & \multicolumn{2}{|c|}{ Especie } & \multicolumn{3}{|c|}{ Talla } & \multirow[t]{2}{*}{ Total } \\
\hline & Machos & Hembras & L. setiferus & F. azetcus & Pequeños & Medianos & Grandes & \\
\hline Pos & $\begin{array}{c}5 \\
(2,84)\end{array}$ & $\begin{array}{c}3 \\
(5,15)\end{array}$ & $\begin{array}{c}4 \\
(5,37)\end{array}$ & $\begin{array}{c}4 \\
(2,62)\end{array}$ & $\begin{array}{c}8 \\
(6,53)\end{array}$ & $\begin{array}{c}0 \\
(0,8)\end{array}$ & $\begin{array}{c}0 \\
(0,66)\end{array}$ & 8 \\
\hline Neg & $\begin{array}{c}59 \\
(61,15)\end{array}$ & $\begin{array}{c}113 \\
(110,80)\end{array}$ & $\begin{array}{c}117 \\
(115,62)\end{array}$ & $\begin{array}{c}55 \\
(56,37)\end{array}$ & $\begin{array}{c}139 \\
(140,46)\end{array}$ & $\begin{array}{c}18 \\
(17,2)\end{array}$ & $\begin{array}{c}15 \\
(14,33)\end{array}$ & 172 \\
\hline Total & 64 & 116 & 121 & 59 & 147 & 18 & 15 & 180 \\
\hline$X^{2}$ & \multicolumn{2}{|c|}{1,564} & \multicolumn{2}{|c|}{0,457} & \multicolumn{3}{|c|}{1,879} & \\
\hline$P$ & \multicolumn{2}{|c|}{0,210} & \multicolumn{2}{|c|}{0,499} & & 0,390 & & \\
\hline
\end{tabular}

Pos: Positivos, Neg: Negativos, $X^{2}$ : Valor de chi-cuadrado, $P$ : Grado de dependencia estadística. Los valores esperados se citan entre paréntesis

(Gutierrez 2009). Incluso, las aves acuáticas puedan ser los vectores que diseminen los agentes etiológicos virales (Lightner et al. 1997, Vanpatten et al. 2004).

La Oficina Internacional de Epizootias (OIE 2008) incluye al IHHNV y TSV en la lista de enfermedades por reunir los criterios de propagación internacional y/o la enfermedad puede afectar a poblaciones naturales de animales acuáticos, las cuales merecen protección por motivos económicos o ecológicos. TSV es la segunda enfermedad en importancia, después del WSSV, ocasionando pandemias en América (Hasson et al. 1999) con pérdidas entre un 40-95\% durante el periodo de 1992 a 1996, valuadas en 1-1,3 mil millones de dólares (Briggs et al. 2005). En Ecuador causó la mortalidad del 75 al $80 \%$ en $L$. vannamei afectando considerablemente la rentabilidad económica de las granjas; de aquí se dispersó rápidamente a Perú. En mayo de 1994 causó pérdidas del 95\% en Hawai (Lightner \& Redman 1998, Vanpatten et al. 2004). A partir del mismo año, colapsó los cultivos de camarón en Colombia, Honduras, Guatemala, El Salvador, Nicaragua, Florida, Brasil, México y Estados Unidos de América (Texas, South Carolina). En 19951996 se reportó en Belice. TSV se consideraba exclusivo del Hemisferio Occidental hasta 1998 (Lightner \& Redman 1998, Briggs et al. 2005), pero debido al movimiento internacional de L. vannamei, se han presentado recientes epizootias en granjas de China, Taiwan y Tailandia (2003), dispersándose a Penaeus monodon (Fabricius, 1798) y Metapenaeus ensis De Hann, 1844 (Chang et al. 2004 Bondad-Reantaso et al. 2005, Briggs 2005, Brock 2008, Stentiford et al. 2009), probablemente por el desarrollo de nuevas cepas del virus, pues $P$. monodon, al igual que Marsupenaeus japonicus
Bate, $1888, F$. duorarum y $F$. aztecus se consideraban altamente resistentes (Lo et al. 2003, Brock 2008). Últimamente afectó cultivos de L. vannamei en Venezuela, de acuerdo a los reportes de Aguado et al. (2008).

Por su parte, en el Continente Americano, IHHNV en L. vannamei y L. stylitostris, fue descrito por primera vez en Hawai en el año 1981, pero análisis recientes de las cepas de IHHNV revelaron que la fuente de la infección original surgió en Filipinas (Briggs el al. 2005). Este virus que se considera enzootico en Asia y América, causó epizootias en Ecuador durante 1997-98, relacionándose con las condiciones oceanográficas y climatológicas por El Niño. La causa mas probable señala a la siembra de las granjas con postlarvas silvestres de $L$. vannamei y L. stylirostris que actuaron como portadores y se diseminaron (Jiménez et al. 1999). Algunos de los valores medios descritos para la prevalencia del IHHNV en reservas silvestres son: $26 \%$ y $46 \%$ en L. stylirostris en las partes inferior y superior del Golfo de California, respectivamente (Pantoja et al. 1999); 28\% en ejemplares de L. vannamei silvestres recogidos de las costas del Pacífico en Ecuador, Colombia y Panamá (Motte et al. 2003). Otros peneidos recogidos durante algunos de estos estudios y que han dado positivo al IHHNV incluyen el camarón marrón (camarón patiamarillo) Farfantepenaeus californiensis y el camarón blanco del oeste del Pacífico L. occidentalis (OIE 2006).

Sobre los casos diagnosticados por histopatología que no lograron confirmarse por RT-PCR, consideramos que la causa fue la insuficiente concentración del ARN de la muestra por el nivel bajo de infección que presentaron los camarones (Lo et al. 1998, Khadijah et al. 2003, 
Galavíz-Silva et al. 2004).

La presencia de estos virus en camarones silvestres sin que muestren lesiones macroscópicas o enfermedad aparente por IHHNV, concuerda con reportes anteriores (Morales-Covarrubias \& Chávez-Sánchez 1999, Pantoja et al. 1999). En el caso de TSV, se ha demostrado que $L$. setiferus puede morir por la infección, pero los sobrevivientes (al igual que $F$. aztecus y $F$. duorarum), no muestran signos macroscópicos y las lesiones histológicas no son siempre evidentes, al menos durante los 79 días de post exposición, por lo cual actúan como portadores del virus (Oversteet et al. 1997). Spann \& Lester (1977) y Bondad-Reantaso et al. (2005) sugieren que los portadores poseen bajas concentraciones de virus y que por ende no muestran signos clínicos aparentes, facilitando su entrada a las granjas, donde infectan a los camarones cultivados, lo cual, aunado al estrés, agrava los procesos infecciosos.

La mayor prevalencia de IHHNV y TSV que se encontró en los meses más fríos, coincide con las observaciones de Aguado et al. (2008) en Ecuador, donde la temperatura mostró una correlación negativa con la prevalencia de los brotes periódicos de TSV en las granjas, pero en el caso de IHHNV se ha reportado que los detonantes principales son las lluvias, disminución de la salinidad y aumento en la temperatura (Jiménez et al. 1999). Por otra parte, no se demostró dependencia significativa de la presencia de los virus con respecto a la talla, sexo y especie, aunque la mayoría de los casos de TSV se encontraron en hembras de L. setiferus y en su totalidad en los de talla pequeña, por lo cual, se esperaba una asociación estadística. Con respecto a IHHNV, no se observaron diferencias importantes en su distribución por especie o sexo, pero los casos se encontraron solo en los de talla pequeña, pero de igual forma, no se demostró asociación estadística por los elevados valores de la significancia. Al respecto, MoralesCovarrubias (1999) reporta el $100 \%$ y $57 \%$, respectivamente, en hembras adultas y en machos adultos de L stylirostris de la región media del Golfo de California (Morales-Covarrubias et al. 1999).

Por lo tanto, se sugiere continuar con análisis de los camarones del Golfo de México en histopatología y PCR para el diagnóstico de etiologías virales e incluso las causadas por bacterias o protozoarios por actuar como portadores, porque se necesita mayor información de patógenos potenciales en camarones silvestres, pues se cuentan con escasos reportes, entre estos sobresalen los realizados en 1995 y 1996 en las costas de Nayarit, México donde se analizaron ejemplares silvestres con la finalidad de usarlos como reproductores, detectándose TSV, IHHNV y parvovirus hepatopancreático asociado a altas mortalidades (Morales-Covarrubias \& ChávezSánchez 1999), sin embargo en el Golfo de México solo se han realizado investigaciones sobre parásitos y simbiontes en crustáceos silvestres, reportándose las descritas por Vidal-Martínez et al. (2002), quienes detectaron a los protozoarios Apiosoma, Epistylis, Zoothamnium penaei, Agmasoma penaei, Thelohania penaei y al céstodo Prochristianella penaei en las especies nativas $F$. aztecus y $F$. duorarum. Por otro lado, Río-Rodríguez et al. (2006) reportaron la primera epizootia en L. vannamei cultivado causada por la bacteria de la necrosis hepatopancreática (NHP), en granjas de Campeche, situado en el Golfo de México, lo que generaría un riesgo y la vulnerabilidad de las especies nativas a contraer enfermedades exóticas, subrayando la necesidad de estudiar las implicancias de la presencia de la bacteria NHP en camarones y otros crustáceos nativos.

\section{Agradecimientos}

Se agradece el apoyo al Programa de Mejoramiento al Profesorado de la Secretaría de Educación Pública (PROMEP) por la beca otorgada al autor F. M. GuzmánSáenz para la realización de su estudio de postgrado. Se agradece también al Postgrado del Doctorado en Ciencias con acentuación en Manejo de Vida Silvestre y Desarrollo Sustentable por el apoyo recibido en la realización de los estudios doctorales. Al Proyecto PAICyT CA170007 por financiar una parte importante del proyecto. Al QBP José Reyes González Galavíz y la Biol. Cecilia Luna Badillo por su importante participación en los análisis de biología molecular. Especialmente agradecemos a los revisores anónimos de este trabajo, cuyas sugerencias enriquecieron este artículo.

\section{Literatura citada}

Aguado-Garcia N, M Boada \& M De Donato. 2008. Detección del síndrome del virus del Taura (TSV) en Litopenaeus vannamei (Boone) del occidente de Venezuela. Revista Científica, Facultad de Ciencias Veterinarias, Universidad del Zulia 23: 134-141.

Bachere E. 2000. Shrimp immunity and disease control. Aquaculture 191: 3-11.

Bell TA \& DV Lightner. 1988. A handbook of normal shrimp. Techniques. Special Publication 1: 2-7. World Aquaculture Society, Baton Rouge.

Bondad-Reantaso MG, SE McGladdery, I East \& RP Subasinghe. 2001. Asia diagnostic guide to aquatic animal diseases. FAO Fisheries Technical Paper 402: 1-240.

Bondad-Reantaso MG, RP Subasinghe, JR Arthur, K Ogawa, S Chinabut, R Adlard, Z Tan \& M Shariff. 2005. Disease and health management in Asian aquaculture. Veterinary Parasitology 132: 249-272. 
Briggs M, S Funge-Smith, RP Subasinghe \& M Phillips. 2005. Introductions and movement of two penaeid shrimp species in Asia and the Pacific. FAO Fisheries Technical Paper 476: 1-78.

Brock JA. 2008. Special topic review: Taura syndrome, a disease important to shrimp farms in the Americas. World Journal of Microbiology \& Biotechnology 13: 415-418

Chang YS, SE Peng, HT Yu, FC Liu, CH Wang, CF Lo \& GH Kou. 2004. Genetic and phenotypic variations of isolates of shrimp Taura syndrome virus found in Penaeus monodon and Metapenaeus ensis in Taiwan. Journal of General Virology 85: 2963-2968.

Dorf BA, C Hons \& P Varner. 2005. A three-year survey of penaeid shrimp and callinectid crabs from Texas coastal waters for signs of disease caused by white spot syndrome virus or Taura syndrome virus. Journal of Aquatic Animal Health 17: 373-379.

Galavíz-Silva L, ZJ Molina-Garza, JM Alcocer-González, J Rosales-Encinas \& C Ibarra-Gámez. 2004. White spot syndrome virus genetic variants detected in Mexico by a new multiplex PCR method. Aquaculture 242: 53-68.

Gutierrez GJ. 2009. Detección y prevalencia de patógenos en Litopenaeus vannamei Boone, 1931 (Curstacea Decapoda) en cultivo y su relación con los parámetros fisicoquímicos y biológicos del agua en el estado de Tamaulipas, México. Memorias del Foro de Seminarios de Postgrado. 2-6 de marzo, 2009. Facultad de Ciencias Biológicas, UANL. México, pp. 1-149.

Jiménez R, R Barniol \& M Machuca. 1999. Infection of IHHNV virus in two species of cultured penaeoid shrimp Litopenaeus vannamei (Boone) and Litopenaeus stylirostris (Stimpson) in Ecuador during El Niño 1997-1998. Aquaculture Research 30: 695-705.

Khadijah S, SK Neo, MS Hossain, LD Miller, S Mathavan \& J Kwang. 2003. Identification of white spot syndrome virus latency-related genes in specific-pathogen-free shrimps by use of a microarray. Journal of Virology 77 : 10162-10167.

Hasson KW, DV Lightner, BT Poulos, RM Redman, BL White, JA Brock \& JR Bonami. 1995. Taura syndrome in Penaeus vannamei: demonstration of a viral etiology. Diseases of Aquatic Organisms 23: 115-126.

Hasson KW, DV Lightner, J Mari, JR Bonami, BT Poulos, LL Mohney, RM Redman \& JA Brock. 1999. The geographic distribution of Taura syndrome virus (TSV) in the Americas: determination by histopathology and in situ hybridization using TSV-specific cDNA probes. Aquaculture 171: 13-26.

Lightner DV. 1996. A handbook of shrimp pathology and diagnostic procedures for diseases of cultured penaeid shrimp, 304 pp. World Aquaculture Society, Baton Rouge.

Lightner DV \& RM Redman. 1998. Strategies for the control of viral diseases of shrimp in the Americas. Fish Pathology 33: $165-180$
Lightner DV, RM Redman, KW Hasson \& CR Pantoja. 1995. Taura syndrome in Penaeus vannamei (Crustacea: Decapoda): gross signs, histopathology and ultrastructure. Diseases of Aquatic Organisms 21: 53-59.

Lightner DV, RM Redman, BT Poulos, LM Nunan, JL Mari \& KW Hasson. 1997. Risk of spread of penaeid shrimp viruses in the Americas by the international movement of live and frozen shrimp. Revue Scientifique et Technique Office International des Épizooties 16: 146-160.

Lightner DV, TA Bell, RM Redman, LL Mohney, JM Natividad, A Rukyani \& A Poernomo. 1992. A review of some major diseases of economic significance in penaeid prawns/shrimps of the Americas and Indopacific. En: Shariff IM, RP Subasinghe \& JR Arthur (eds). Diseases in Asian Aquaculture, pp. 57-80. Asian Fisheries Society, Manila.

Lo CF, YS Chang, CT Cheng \& GH Kou. 1998. PCR monitoring of cultured shrimp for white spot syndrome virus (WSSV) infections in growout ponds. En: Flegel TW (ed). Advances in shrimp biotechnology, pp. 281-286. National Center for Genetic Engineering and Biotechnology, Bangkok.

Lo CF, YS Chang, SE Peng \& GH Kou. 2003. Major viral diseases of Penaeus monodon in Taiwan. Journal of the Fisheries Society of Taiwan 30: 1-13.

López-Téllez A, VM Vidal, RM Overstreet. 2009. Seasonal variation of ectosymbiotic ciliates on farmed and wild shrimps from coastal Yucatan, Mexico. Aquaculture 287: 271-277.

Lotz JM, AM Flowers \& V Breland. 2003. A model of Taura syndrome virus (TSV) epidemics in Litopenaeus vannamei. Journal of Invertebrate Pathology 83: 168-176.

Molina-Garza ZJ, L Galaviz-Silva, JL Rosales-Encinas \& JM Alcocer-González. 2008. Nucleotide sequence variations of the major structural proteins (VP15, VP19, VP26 and VP28) of white spot syndrome virus (WSSV), a pathogen of cultured Litopenaeus vannamei in Mexico. Journal of Fish Diseases 31: 197-203.

Morales-Covarrubias M \& C Chávez-Sánchez. 1999. Histopathological studies on wild broodstock of white shrimp Penaeus vannamei in the Platanitos area, adjacent to San Blas, Nayarit, Mexico. Journal of the World Aquaculture Society 30: 192-200.

Morales-Covarrubias M, LM Nunan, DV Lightner, JC Mota-Urbina, MA Aguirre-Garza \& C Chávez-Sánchez. 1999. Prevalence of infectious hypodermal and hematopoietic necrosis virus (IHHNV) in wild adult blue shrimp Penaeus stylirostris from the Northern Gulf of California, Mexico. Journal of Aquatic Animal Health 11: 296-301.

Motte E, E Yugcha, J Luzardo, F Castro, G Leclercq, J Rodriguez, P Miranda, O Borja, J Serrano, M Terreros, K Montalvo, A Narvaez, $N$ Tenorio, $V$ Cedeño, $E$ Mialhe \& V Boulo. 2003. Prevention of IHHNV vertical transmission in the white shrimp Litopenaeus vannamei. Aquaculture 219: 57-70. 
Nunan LM, BT Poulos \& DV Lightner. 1998. Reverse transcription polymerase chain reaction (RT-PCR) used for the detection of Taura syndrome virus (TSV) in experimentally infected shrimp. Diseases of Aquatic Organisms 34: 87-91.

Nunan LM, SM Arce, RJ Staha \& DV Lightner. 2001. Prevalence of infectious hypodermal and hematopoietic necrosis virus (IHHNV) and white spot syndrome virus (WSSV) in Litopenaeus vannamei in the Pacific Ocean off the coast of Panama. Journal of the World Aquaculture Society 32: 330-334.

Ocaña-Luna JA. 1999. Diversidad del ictioplancton en las lagunas Madre y Almagre, Tamaulipas y Laguna de Tampamachoco, Veracruz. Proyecto CONABIO FB440/ LO70/97. Comisión Nacional para el Conocimiento y Uso de la Biodiversidad, México, pp. 1-54.

OIE. 2006. Manual of diagnostic tests for aquatic animals, 469 pp. World Organization for Animal Health (OIE), Paris.

Ossiander FJ \& G Wedermeyer. 1973. Computer program for sample size required to determine disease incidence in fish populations. Journal of the Fisheries Research Board of Canada 30: 1383-1384.

Overstreet RM, DV Lightner, KW Hasson, S Mcilwain \& J Lotz. 1997. Susceptibility to Taura syndrome virus of some penaeid shrimp species to the Gulf of Mexico and the Southeastern United States. Journal of Invertebrate Pathology 69: 165-176.

Páez-Osuna F. 2005. Retos y perspectivas de la camaronicultura en la zona costera. Revista Latinoamericana de Recursos Naturales 1: 21-31.

Pantoja CR, DV Lightner \& KH Holtschmit. 1999. Prevalence and geographic distribution of infectious hypodermal and hematopoietic necrosis virus (IHHNV) in wild blue shrimp Penaeus stylirostris from the Gulf of California, Mexico. Journal of Aquatic Animal Health 11: 23-34.

Pérez-Farfante I. 1988. Illustrated key to penaeid shrimp of commerce in Americas. NOAA Technical Report NMFS 64: $1-32$.

Primavera JH \& ET Quinitio. 2000. Runt-Deformity Syndrome in cultured giant tiger prawn Penaeus monodon. Journal of Crustacean Biology 20: 796-802.

Río-Rodríguez RE, S Soto, M Lara-Flores, AD Cu-Escamilla \& MI Gomez-Solano. 2006. A necrotizing hepatopancreatitis (NHP) outbreak in a shrimp farm in Campeche, Mexico: A first case report. Aquaculture 255: 606-209.
Rodriguez J \& G Le Moullac. 2000. State of the art of immunological tools and health control of penaeid shrimp. Aquaculture 191: 109-119.

Sambrook J \& D Russell. 2001. Molecular cloning: A laboratory manual, pp. 12.74-12.75. Cold Spring Harbor Laboratory Press, New York.

Saulnier D, P Haffner, C Goarant, P Levy \& D Ansquer. 2000. Experimental infection models for shrimp vibriosis studies: a review. Aquaculture 191: 133-144.

Spann KM \& RJ Lester. 1997. Viral diseases of penaeid shrimp with particular reference to four viruses recently found in shrimp from Queensland. World Journal of Microbiology and Biotechnology 13: 419-426.

Stentiford GD, JR Bonami \& V Alday-Sanz. 2009. A critical review of susceptibility of crustaceans to Taura syndrome, Yellowhead disease and White Spot Disease and implications of inclusion of these diseases in European legislation. Aquaculture 291: 1-17.

Tang KFJ \& DV Lightner. 2001. Detection and quantification of infectious hypodermal and hematopoietic necrosis virus in penaeid shrimp by real-time PCR. Diseases of Aquatic Organisms 44: 79-85.

Teunissen OSP, R Faber, GH Booms, T Latscha \& JH Boon. 1998. Influence of vaccination on vibriosis resistance of the giant black tiger shrimp Penaeus monodon (Fabricius), Aquaculture 164: 359-366.

Van de Braak CBT, MHA Botterblom, EA Huisman, JH Rombout \& WP van der Knaap. 2002. Preliminary study on haemocyte response to white spot syndrome virus infection in black tiger shrimp Penaeus monodon. Diseases of Aquatic Organisms 51: 149-155.

Vanpatten KA, LM Nunan \& DV Lightner. 2004. Seabirds as potential vectors of penaeid shrimp viruses and the development of a surrogate laboratory model utilizing domestic chickens. Aquaculture 241: 31-46.

Vidal-Martínez VV, AM Jiménez-Cueto \& R Simá-Alvarez. 2002. Parasites and symbionts of native and cultured shrimps from Yucatán, Mexico. Journal of Aquatic Animal Health 14: 57-64.

Wakida-Kusonovi A, L García-Solorio \& NG Vázquez Benavides. 2008. Abundance of the comercial penaeid shrimp juveniles in the North zone of Laguna Madre, Mexico. Hidrobiológica 18: 85-88. 